\section{PHYSIOLOGY OF ASPHYXIA.}

\section{To the Editor of The La NCET.}

Srr,-As the cditor of a distinguished medical publication, I deem it necessary to address you on a subject, which has not only reference to myself, but, in some respect, to medical literature. Presuming it likely that the work on "The Physiology, Pathology, and Treatment of As. phyxia," just published by Dr. Kay of Manchester, may be reviewed in your Journal, I am desirous of putting you in possession of certain circumstances connected with his subject. I may remark, though familiar to you, that, until lately, Bichat's views of the nature and cause of asphyxia were considered the most probable and best established; hence they were those that were taught and admitted in our colleges and medical writings.

In a paper, "On the Cause and Effects of an Obstruction of the Blood in the Lungs," published in the 19th vol., 1823, of the Edinburgh Med. and Surg. Journal, I have given an account of a series of experiments which I had performed. From phenomena which were witnessed in those experiments, I deduce-" that the obstruction of the blood in the lungs, on suspension of respiration, is not the effect of a mechanical cause - that is, of collapse or subsidence of the lungs; that the obstruction of the blood in the lungs, on suspension of respiration, arises from a deprivation of pure atmospherical air." From these deductions, and the factsthat an animal can survive only a very limited time the suspension of the function of respiration; and that the blood undergoes a wonderful change, in consequence of its being acted upon by the inspired air; I infer, " that the blood cannot pass from the system of the pulmonary artery into that of the pulmonary veins, without first undergoing those urknown changes from the action of the inspired air."

In my paper I have noticed, that Harvey supposed the circulation in asphyxia to be arrested in the lungs; Goodwyn and Bichat in the heart: that Harvey attributed the vacuity of the aortic system after death to an obstruction of the blood in the lungs, in consequence of their collapse: that Goodwyn and Bichat concurred in imagining asphyxia to be immediately dependent upon the circulation of black blood, or blood of a renous character,the left ventricle, according to Goodwyn, ceasing to act " from a defect of a stimulating quality in the blood itself ;" the heart ceasing to act, according to Bichat, from the circulation of black blood (sang noir) in the coronary arteries, that fluid stopping (empeche) the action of its fibres. The error of these sereral views I have pointed out, and, in conclusion, I have advanced the theory, that the immediate cause of the cessation of the action of the heart, on suspension of respiration, arises from the obstruction to the circulation in the lungs, not from a state of collapse of those organs, as supposed by Harvey, but from a deprivation of pure atmospherical air. Further, I have cursorily examined how far the obstacle to the circulation of the blood, from a deficiency of pure atmospherical air, is adequate to explain the cause of some of the vital phenomena observed in health and disease.

My paper, as I have above stated, appeared in the 19th volume, 1823, of the Edinburgh Medical and Surgical Journal. In the 29th volume, 1828, of the same journal, Dr. Kay published an essay, entitled, "Physiological Experiments and Observations on the Cessation of the Contractility of the Heart and Muscles in the Asyphyxia of Warm-blooded Animals," in which be develops the same views with respect to the immediate cause of the cessation of the heart, as I had already done, by a sinilar or analogous series of experiments. In this essay, no reference is made to my paper, which had appeared in the same journal four years previously. This circumstance I mentioned to Dr. Kay. Dr. Kay, in 1831, published, "Further Experiments on Suspended Animation," in the North of England Medical and Surgical Journal; in that essay, in a marginal note, Dr. Kay says, that I had called his attention to my paper, and states $m y$ having anticipated him in one of his conclusions, namely, "That the obstruction of the blood in the lungs, on suspension of respiration, arises from a deprivation of pure atmospherical air." This marginal note is copied into Dr. Kay's recently published volume on the Physiology, \&c. of Asphyxia. However, though Dr. Kay enters rery elaborately into the history of asphyxia in this volume, yet no notice whatever is taken of my having questioned the correctness of Bichat's hypothesis, nor of $\mathrm{my}$ having advanced the theory, - that the immediate cause of the cessation of the action of the heart, or asphyxia, or suspension of respiration, is the effect of the circulation being obstructed in the lungs.

I regret that any circumstances should arise to render it imperative on me to make this communication. But, in consequence of the author of the article on "Asphyxia," in the Cyclopedia of Medi- 
cine, and the reviewer of Dr. Kay's recent work, in the Liverpool Medical Journal, having given Dr. Kay exclusively the credit for being the first who pointed out estabe middle part established, that the immediate cause of of the nail which had been divided in a asphyxia is the obstruction to the circula- line parallel to its upper edge. At each tion in the limgs, 1 deem it incumbent on me, in my own defence, to set the profession right on these points. I am, Sir,

Your very obedient serrant,

Davin Williams, M.D.

Liverpool, May 12th, 1834 .

P.S. Should the suhject of asphyxia be hereafter reviewed in your journal, I trust the reviewer will take the trouble of examining the papers alluded to, and thereby satisfy himself of the accuracy of this statenient, and do justice accordingly.

\section{PORTION OF FINGER, COMPLETELY} SEPARATED

FOR MORE THAN HALF AN HOUR, AND

\section{AFTERWARDS UNITED,}

THOUGH IN AN INCOAPLETE MANNER.

Cases of this kind are so rare, or are related on such doubtful authority, that unany surgeons are still inclined to deny the possibility of reunion of a divided part, when any length of time has elapsed after its complete separation from the body. The following case occurred not long ago at one of the Parisian hospitals, and presents a remarkable example of the power which nature is capable of exercising on certain occasions in the reunion of divided parts. Its authenticity is beyond question. It is related by M. BEAU interne at the Salpetriere, Paris, in the $A r$ chives Général for March:-

On the 7 th September, 1833, a quarter after six in the morning, Marianne Daune, aged 41 years, house-maid at Salpetrière, a girl of good strong constitution, and very sanguine temperament, while cutting bread for the paticnts, accidentally wounded the thunb of the left hand. The force of the cut was sufficient to divide the finger completely, and its extrenity was frojected several inches from the bod $;$, on the table. Another woman, who happened to be present, took up the divided mor$\mathrm{scl}$, and wrapped it in a piece of paper to kcep for the interne, who dill not arrive until half an hour aftorwarts. dorsal to the palmar surface, and com.

On examination, M. Beau found a clean wound, embracing the whole thickness of the thumb, passing obliquely from the pulsation of the heart a small jet of blood was discharged, to arrest which the hand was plunged in cold water. The separated end of the thumb was pale and cold, one fourth of an inch long on the dorsal surfacc, and three lines and a half on the opposite side. The divided edge was cleariy cut, but covered by dust. M. Beau having conceived the idea of attempting reunion, moistened the morsel of flesh in warm water, removed the dust as carefully as possible, and having cleared the wound with a sponge, he placed the divided surfaces in perfect apposition ; the parts were kept in contact with five slips of diachylon plaster, some lint and compresses. During the whole of the 7 th, there was severe pulsating pain in the thumb, extending up to the shoulder, ard preventing the patient from sleeping. 8th. Fever and thirst. sth. Less fever. 10th. No pain; rested well all night. On the 15 th the dressings were removed; the lint was dry, and it was found that the end of the finger was unised slightly at the palmar surface to the thumb. On the dorsal surface the parts were still capable of some separation; the nail and epidermis were black; no trace of suppuration. The finger was now plunged for two or three minutes in warm wine, and dressed in the same manner as before.

18th. No bad odour or suppuration; the adhesions formed are stronger; there is a little dark serous fiuid interposed between the edges of the nail.

20th. The nail and epidermis were removed by exercising gentle traction. The finger now presented the following appearance:-The summit of the phalanx, dorsal surface, is not united to the rest of the bone; it is necrosed, dark, and moveable, being merely retained in siiu by the soft parts, which are in a state of gangrene. A gray adhesive eschar forms round, and below it a horse-shoe line, very narrow. The corresponding surface of the phalanx is exposed, and does not present any appearance of vascular granulations; but on the lateral and dorsal surfaces, the skin of the divided morsel is continuous on all points with the rest of skin; the bond of union is traced by a semicircular line, not well marked, though prominent. Here the skin is red and sinooth, forming a crescent two lines and a half brcad in the middie, and gradially dim- 